\title{
Evaluation of the quality of life of children in terms of health as an interdisciplinary problem
}

\begin{abstract}
The aim of the paper was to present the basic methodological approaches to studying the quality of life of patients with regard to interdisciplinary character of the concept, its interrelation with standard of living, specificity in children and teenagers.

Studying the quality of life of children and teenagers has specific character. According to modern recommendations, it is the basis of complex estimation of state of health of the child. Two basic methodological approaches are used: the first consists in selection and analysis of factors, significant for health of teenagers from adult people point of view; the second provides research of factors, significant from the point of view of teenagers. Techniques unite two types of criteria: 1. the objective: physical activity, social functioning; 2 . the subjective: factors of emotional status, self-estimation of state of health, satisfaction by factors related with health, - that is perception by teenagers how their requirements for health are satisfied and how much possibilities necessary for it are given.
\end{abstract}

Keywords: health, quality of life, factors, child, child care.

DOI: $10.2478 /$ pjph-2014-0033

The concept quality of life was developed by sociologists in 1960s. Simultaneously it became a subject of psychology and economy. In modern clinical medicine and public health, the term "the quality of life connected with health" has received attention. The purpose of the work was to present the basic methodological approaches to studying quality of life in medicine with the account of interdisciplinary character of the concept, its interrelation with standard of living, specificity in children and teenagers.

Quality of life as the subject of studying of a complex of social sciences

Evolution of paradigms of clinical medicine of the twentieth century proceeded in parallel with tendencies of change of public health. The majority of physicians believed approximately to the middle of the 20th century, that the most part of diseases depends on internal factors: heredities, deterioration of protective forces of an organism and others, though already at the beginning of the century there was a belief about a primacy of external factor [1]. In 1960-1970, when the doctrine about epidemiology of non-epidemic diseases got popularity, in parallel with a substantiation of system of risk factors for health, the concept of social conditionality of health was proved. WHO expands health definition as a condition of physical, psychological and social well-being, instead of absence of illnesses. The concept of social conditionality of health initiated the development of a new paradigm of clinical medicine - concepts of quality of life. WHO recommends considering quality of life as the degree of perception by separate people or groups of people that their requirements are satisfied, and possibilities necessary for achievement of well-being and self-realization are represented [2]. In other words, quality of life is the degree of comfort of the person both in itself and within the limits of the society [3].

Working out in the sociology of the concept quality of life has begun on the basis of concept social indicators (F. Konvers, U. Rodzhers, L. Milbrejt, A. Mak-Kennel, S.Rajt). Simultaneously quality of life became a subject of research for other sciences: psychology, economy. Psychologists have mainly focused attention on affective and cognitive structural components of quality of life [4]. Sociologists have presented subjective and objective components of quality of life that has led to occurrence of corresponding methodological approaches. Subjective approaches to studying the quality of life in sociology have concentrated on consideration of valuable attitudes and experiences [5], while objective approaches were based on such components as food, habitation, education [6]. Case elements of structure of quality of life, according to the first approach, are the state of health, satisfaction of life; according to the second one, quality of life is defined as quality of social and physical environment in which people try to satisfy their needs and requirements [7].

The first basic positions of the concept of quality of life in medicine included the postulate that the universal criterion including the characteristics of a condition of at least of four components of well-being: physical, psychological,

${ }^{1}$ Chair and Department of Public Health and Health Protection Management, Grodno State Medical University, Belarus

${ }^{2}$ Chair and Department of Epidemiology, Medical University of Lublin, Poland 
social and spiritual, is necessary for an estimation of a condition of the person. This criterion was also considered as substantial concept of quality of life [8]. For an average person the quality of life is related to health, successful family life, self-esteem, good social contacts, competence to cope with difficult situations, sense of security [9].

The term "quality of life related with health" was offered by Kaplan and Bush in 1982 for the first time to distinguish the aspects concerning a state of health and care of it basing on the wide general concept of quality of life [10]. M. Shumaker and Naughton gave the formulation of this concept in 1995: the quality of life related with health is an estimation of the subjective factors defining people's health at present, care of health and the actions promoting its strengthening; ability to reach and support such level of functioning which would allow them to follow life purposes and would be reflected by level of their well-being [11].

According to Russian authors' definitions, quality of life related with health means a category including a combination of the conditions of life-support and state of health, allowing to reach physical, mental, social well-being and selfrealization [12].

The studies of life quality in medicine provide data on the situation of patients. They facilitate seeing the problems of patients and allow for taking up activities focused on solving them [13]. As A. A. Novik, T. I. Ionova specify, the concept of quality of life in medicine includes three basic components: multidimensionality (quality of life bears the information about all basic spheres of ability to live of the person); convertibility in time (quality of life changes in time depending on the condition of the patient, data about quality of life allow to carry out monitoring and to spend treatment and rehabilitation correction in case of need); participation of the patient in the estimation of its condition [8].

Variety of the social sciences where health of the person became the subject of studying are focused on studying the quality of life as an integral parameter connected with health. I.V. Zhuravlyova has shown that the indicator of individual's satisfaction of health is an integrated psycho-social empirical indicator. On the one hand, it characterizes a selfestimation of health and the attitude of the individual to the self-estimation. On the other hand, it is in difficult interaction with estimations of parameters of quality of life [14]. The quality of life related with health can be indirectly characterized by the indicator of satisfaction of health.

The interrelation of life satisfaction with health is shown by Nazarova's works. I. B. Nazarova states: health is one of indicators of quality of life [15]. Relationship of quality of life and health is explained by sociological theories of health, such as the theory of human and social capital, the theory of social status, the theory of inequality and social justice. Special value is given to measurement of ability to work. It is necessary to notice, that the factors connected with disability are the cores in estimations of social, medical and economic efficiency of public health services. Quality of life can be considered through health-maintaining behavior also. The assumption is based on the model which connects relations between health behavior and health level, level of health and perceived quality of life [16].

\section{Level and quality of life: the example of Belarus}

The Republic of Belarus is the country with transition to the postindustrial model of economy. There is a shift from processing branches to sphere of innovative types of service. The new type of society stratification is formed. But the postindustrial society is defined not only by innovations in various spheres and information variety. It is defined by highly demanded innovative services: humanitarian and professional, concentrated around two fundamental spheres, as health and education [17]. Level and quality of life are considered as transition preconditions to the postindustrial society.

The standard of living expresses security of the population by the consumer blessings, which are characterized by the quantity indicators abstracted from their qualitative values. In a context of statistics, they are defined by a condition of services in comparison with the international standards. Quality of life is a category expressing degree of satisfaction of different groups of the population with conditions of the ability to live, and also the degree of self-realization in work and degree of consumption of innovative types of service [18]. The quantity and quality are composite elements of the mechanism of the developments, measured in different indicators but passing each other. Quantitative changes, falling outside the limits of the certain category, which are for them a measure, turn to qualitative changes [19].

The Republic of Belarus from 1992 until 2009 was included in a group of the countries with a high level of development, however its rating has decreased from 42nd position in 1992 to 68th in 2007. The reason of the drop is the negative dynamics of life expectancy. This parameter was about 71.1 years in 1992 and only 69.0 years in 2007 . Negative dynamics was observed against growth of other indexes of development of the country. So, the educational level has raised from $98.1 \%$ in 1992 to $99.7 \%$ in 2007 ; gross national product size per capita for the analyzed period increased almost 2 times (6440 US dollars in 1992 and 10841 US dollars in 2007). Despite the growth of gross national product, the country does not manage to support the same rates of growth of a standard of living of the population as in economically developed countries, therefore the dynamics of rating on an index of development of human potential for Belarus since 1992 till 2007 was negative (-26 points). It means that Belarus, remaining in a group of the countries with a high level of development, gradually concedes to them on the basic indicators of this development, first of all, on life expectancy [20].

\section{Questionnaire as the unique tool of research. Specificity for children and teenagers}

Despite a variety of techniques, the unique tool of research of quality of life is the questionnaire. There are some classifications of questionnaires on studying the quality of life in medicine, depending on research directions. We can distinguish general and special questionnaires; the last, in turn, are subdivided into medicine areas, or studied nosology. Distinction is also due to the questionnaires specific to a certain condition $[21,22]$. Unlike special, the general questionnaires allow for estimating quality of life both of healthy subjects and patients, irrespective of the disease. 
As a whole, the general techniques for studying quality of life in interrelation with health is association of the analysis of conditions, a way of life and satisfaction with them. Three given components are key factors in the estimation of quality of life. At the same time, quality of life is a category characterizing not so much interests and values of the individual and a society, as the requirements. N. S. Danakin writes: quality of life characterizes the structure of requirements of the person and possibility of their satisfaction [23]. An important place in the structure of requirements of the person and a society is occupied by the requirements connected with health. In turn, requirements are the regulator of behaviour. Therefore, we should include factors of style of life and health behavior in the study of quality of life related with health.

The most widespread approaches to studying health of teenagers in the sociology are biological, cognitive, psychosexual and social ones; and from sociology of medicine point of view the last is the most important [24]. The social approach to studying teenagers is directed on research of ability of teenagers to understand social relations and to understand other people. Complexity and duration of the process of acquisition of social knowledge is underlined. The approach is based on physical, psychological and social features of the teenager: active hormonal processes, dependence on the big number of microsocial factors of environment (family, school, nearest environment) and macrosocial factors (society, culture), active knowledge of a role of the person in the society and ways of its realization, perception of valuable attitudes and behavioral norms to various spheres, including health sphere. Not being able to estimate objective processes, the teenager is rather vulnerable to influence of a social and information environment $[25,26]$.

Two basic methodological approaches to studying of health of teenagers, are mentioned by I. V. Zhuravlyova [24]. The first approach consists in selection and the analysis of factors, significant for teenagers' health from the point of view of adult people. It is characteristic that conclusions, as a rule, are connected with absence at teenagers of requirement for various forms of care about health and insufficient sensibleness of value of negative factors for health. The second approach provides research of factors, significant from the point of view of teenagers. I. V. Zhuravlyova. includes here knowledge concerning reproductive and sexual health (medical knowledge), general data about the place of the teenager in a society, in an adult life, about ways of adaptation to it. The important role is played by understanding and support of the teenager by parents, peers, in other words, by social support.

Methodological approaches to studying of health of teenagers in medicine in modern conditions are characterized by the increasing social orientation [27]. Common problem in quality of life of teenagers related with health studying is absence of the unified validated questionnaire. Among the techniques developed by Belarussian scientists, none has received the standard status. At the same time, the number of works as, for example, developed in The Belarusian Medical Academy of Post-Graduated Education "The Method of an estimation of individual quality of life", deserve more steadfast studying [28].
Leading paediatrists state the necessity of quality of life research for an estimation of health status of children: introduction of an indicator of quality of life as additional criterion will allow to modify an existing technique of a complex estimation of state of health of children and to make it at new, modern level with application of the international approaches, and the use of standard toolkit will make research comparable in any territory [29].

Questionnaires for children from the birth till 18 years of age have been developed for a complex individual estimation of state of health of children for Russia [30,31]. Blocks for estimation of a disease and of social status of family of the child have been created, along with blocks for physical, psycho-emotional, social functioning and intellectual development with an estimation of ability to study, unlike foreign samples. The obtained data testify that the value of the account of social environment and external factors (the status and level of income of a family per one member, character of habitation and family microclimate)are important, and sometimes solving validity for indicators of quality of life of children.

The analysis of quality of life in paediatrics allows to investigate not only clinical, but also such social aspects of health of children, as perception by the child of world, the relation of the child to disease and treatment, occurrence in the family of psychological and social problems in case of the child's disease, a condition of "optimum health" from the point of view of the child and his parents [12]. It is especially important for estimation of reproductive health. So, considering reproductive health and sexual behavior of teenagers, I. V. Zhuravlyova is focused on medical-social context of research in the given area and gives great value to such factors as knowledge of teenagers and sources of gaining information, the risky sexual behavior interfaced to a number of social problems, social risk factors of early sexual experience (such as family type, influence of a society of contemporaries and others) $[32,33]$.

\section{CONCLUSIONS}

Along with the statement, that quality of life is the universal criterion of well-being, in interrelation with health, it is the basis to understand the illness and to estimate its treatment efficiency. The concept of quality of life in medicine includes such components, as multidimensionality, convertibility in time, and participation of the patient in the estimation of his/ her condition. The unique tool of quality of life research is the questionnaire. The analysis of conditions of life, way of life and life satisfaction is general for the all of them. At the same time, quality of life is the category characterizing not so much interests and values of the individual and society, but their requirements. Therefore studying quality of life related with health should include behavioral factors.

Quality of life is the basis of complex estimation of state of health of the child. Two basic methodological approaches are used: the first consists in selection and analysis of factors, significant for health of teenagers from adult people point of view; the second provides research of factors, significant from the point of view of teenagers. The techniques unite two 
types of criteria: objective (physical activity, social functioning); subjective (factors of emotional status, self-estimation of state of health, satisfaction by factors related with health), - that is perception by teenagers how their requirements for health are satisfied and how much possibilities necessary for it are given.

Thus, the quality of life is a subject of complex of social sciences. Achieving its possible high level is the purpose of practical application of results of this research. For the majority of the countries of the Post-Soviet territory, as well as for Belarus, the problem of a mismatch of level and quality of life is current. The interrelation of a problem of mismatch of level and quality of life and a problem of deterioration of health of the population and negative dynamics of life expectancy is thus obvious.

\section{REFERENCES:}

1. Lisitcyn YP. Theories of medicine of the XX-th century. Moskow: Medicine; 1999.

2. Health-21: Bases of a policy of achievement of health for all in the European region WHO. The European series on achievement of Health for all. 1999;6:293.

3. Kovyneva OA. Structure of quality of life and factors of its increase. Public health services economy. 2006;8:48-50.

4. Abbey A, Andrews F. Modeling the Psychological Determinants of Life Quality. Soc Indic Res. 1985;16:1-34.

5. Shuessler KF, Fisher GA. Quality-of-life research and sociology. An Rev Soc 1985;11:131.

6. Wingo L. The Quality of Life: Toward a micro-economic definition. Urban Stud. 1973;10:3-8.

7. Nugaev RM, Nugaev MA. Quality of life in works of sociologists of USA. Sociol. 2003;6:100-5.

8. Novik AA, Ionova TI. Management on research of quality of life in medicine. Moskow: The Star World; 2002.

9. Kochman D. Jakość życia. Analiza teoretyczna. Zdr Publ. 2007;117(2):242-8.

10. Tatskova AY, Chechelnickaya SM, Rumyantceva AG. To the question on a technique of estimation of health-related quality of life. Problems of social hygiene, health services and history of medicine. 2009;6:46-51.

11. Tonnel AB, Marquette C, Wallaert B. Rev Prat. 1992;42(19):2399-404.

12. Medik VA, Yuriev VK. Course of lectures on public health and health services. Moskow: Medicine;2003.

13. Trojanowska A. Znaczenie badan nad jakością życia w medycynie. Zdr Publ. 2011;121(1):99-103.

14. Zhuravlyova IV. The attitude to health of individual and society. Moskow: Science; 2006.

15. Nazarova IB. Health of workers. Moskow: MAKS Press; 2007.

16. Woodruff SI, Conway TL. Impact of Health and Fitness-Related Behavior on Quality of Life. Soc Indicators Res. 1992;25:391-405.
17. Sokolova GN, Sechko NN, Taranova EV. Level and quality of life as transition preconditions to a postindustrial society. Sociol. 2010;4:4252 .

18. Sokolova GN. Social indicators of innovative development: interrelation dialectics. Proceedings of the International Scientifically-practical Conference: Problems of the theory and practice of formation of Belarussian economic model; 2008 May 30th; Minsk, Institute of economy of National Academy of Science, Minsk: Belarus. Minsk: Publishing of House Institute of economy of National Academy of Science of Belarus; 2008.

19. Sokolova GN. Formation of postindustrial society: the Belarussian phenomenon. Sociology RoSA. 2009;4:81-9.

20. Sokolova GN. The human capital as an economic category of the present. Scie innov. 2010;6:57-9.

21. Babak GA. Quality of life of patients with rheumatic arthritis. Medi news. 2005;2:96-100.

22. Cyrulnikova AN. Quality of life of patients with chronic heart insufficiency at an arterial hypertensia and ischemic illness of heart. Med news. 2004;4:83-5.

23. Danakin NS. To the definition of quality of life. Quality of life of population: indicators and increase ways. The collection of proceedings. Belgorod: Publishing house; 2004.

24. Zhuravlyova IV. Health of teenagers: the sociological analysis. Moskow: Publishing house of Institute of sociology of the Russian Academy of Sciences; 2002

25. Papura AA. Influence of mass media on psychological development of the person of the teenager. Proceedings of II International scientific conference. Psychosocial adaptation in a transformed society: problems and prospects. 2007 October 26th; Minsk, Belarus. Minsk: Publ. Centre of BSU; 2007.

26. Chistov AV. The analysis of influence of mass-media on mental health and development of the person. Proceedings of II International scientific conference. Psychosocial adaptation in a transformed society: problems and prospects. 2007 October 26th; Minsk, Belarus. Minsk: Publ. Centre of BSU; 2007.

27. Sygit K. Koncepcja autorskiej „Skali do oceny zachowań zdrowotnych młodzieży”. Projekt i wstępne wyniki z wdrożenia. Zdr Publ 2008;118(4):417-20.

28. Maschenko IV. Method of an estimation of individual quality of a life [Internet]. Minsk: BelMAPO [www.belmapo.by/page/5/390]

29. Albitskiy VY, Vinjarskaja IV. The new approach in a complex estimation of state of health of children with use of criterion of quality of life. Problems of social hygiene, health services and history of medicine. 2007;5:16-7.

30. Bahadova EV. The new approach to definition of health of children with application of a technique of an estimation of quality of life [Internet]. Moskow: Vestnik. [vestnik.mednet.ru].

31. Tcybulskaja IS, Bahadova EV. Medical-biologic and social adaptation in population of children in modern conditions (specifications and deviations). Moskow: RIO CNIIOIZ; 2006.

32. Zhuravlyova IV. Behavioural factors of health of teenagers. Sociol Med. 2002;1:32-48

33. Zhuravlyova IV. Reproductive health of teenagers and problem of sexual education. Sociol. 2004;7:133-42.

\section{Corresponding author}

Halina Piecewicz-Szczęsna

1 Chodźki Str., Lublin 20-093, Poland

tel./fax 081 742-37-71

E-mail: halpiec@wp.pl 